\title{
TRANSCRANIAL DOPPLER PADA SEREBRAL ARTERIOVENOUS MALFORMATION LAPORAN KASUS
}

Esdras Ardi Pramudita Bagian Neurologi, RS Panti Rapih, Yogyakarta

Korespondensi: esdras.pramudita@yahoo.com.sg

\begin{abstract}
ABSTRAK
Serebral Arteriovenous Malformation (AVM) merupakan suatu kelainan pada formasi pembuluh darah di otak. Keadaan dinding pembuluh darah yang terbentuk pada AVM tidak sebaik dengan pembuluh darah normal sehingga mudah pecah dan menimbulkan masalah intraserebral. TCD merupakan suatu pemeriksaan berbasis ultrasound yang bersifat non invasif, murah dan real time dalam memeriksa kondisi hemodinamik intraserebral dan TCD dapat digunakan untuk menentukan feeder artery pada serebral AVM. Melaporkan dua kasus Serebral AVM selama bulan Juli-September 2016 di RS Panti Rapih Yogyakarta dari kedua kasus didapatkan peningkatan Mean Flow Velocity (MFV) dan penurunan Pulsatility Index (PI) $<0,5$ pada Right Anterior Cerebral Artery (R-ACA) dari kasus pertama dan Left Middle Cerebral Artery (L-MCA) dari kasus kedua yang menunjukkan bahwa arteri-arteri ini sebagai feeder artery
\end{abstract}

Kata Kunci: Arteriovenous malformation, Transcranial Doppler, Feeder Artery. 


\title{
TRANSCRANIAL DOPPLER IN CEREBRAL ARTERIOVENOUS MALFORMATION \\ CASE STUDY
}

\author{
Esdras Ardi Pramudita \\ Neurology Division, Panti Rapih Hospital, Yogyakarta \\ Correspondence: esdras.pramudita@yahoo.com.sg
}

\begin{abstract}
Cerebral Arteriovenous Malformation (AVM) is a anomalies in the formation of cerebral blood vessels. The blood vessels wall formed on the AVM is not as good as normal blood vessels that can break easily and cause intracerebral bleeding. Transcranial Doppler (TCD) is an ultrasound-based examination which is noninvasive, cheap and real time for checking the condition of intracerebral hemodynamics and TCD can be used to determine the feeder artery cerebral AVM. Reported two cases of Cerebral AVM during July-September 2016 in Panti Rapih Hospital Yogyakarta. In this cases associated with an increase Mean Flow Velocity $(M F V)$ and decreased Pulsatility Index $(P I)<0.5$ at Right Anterior Cerebral Artery $(R-$ $A C A)$ on the first case and Left Middle Cerebral artery (L-MCA) on the second case which indicate a feeder artery.
\end{abstract}

Keywords: Arteriovenous Malformation, Transcranial Doppler, Feeder Artery. 


\section{PENDAHULUAN}

\section{Serebral}

Malformation (AVM)

keadaan anomali

Arteriovenous

adalah suatu dari tahap perkembangan pembuluh darah di otak. arteri dengan diameter besar yang kaya akan oksigen mengalir langsung ke vena tanpa melalui fase kapiler, Serebral AVM dapat terbentuk diberbagai tempat tetapi lokasi paling sering adalah Arteri Serebri Media. ${ }^{1}$

Keadaan dinding pembuluh darah yang terbentuk pada AVM tidak sebaik dengan pembuluh darah normal sehingga mudah pecah dan menimbulkan perdarahan intraserebral. Manifesasi klinis serebral AVM yang paling sering adalah perdarahan intraserebral (40$60 \%$ ) dan $30 \%$ dari perdarahan intraserebral pada AVM mengalami kejang. ${ }^{1}$

Terdapat berbagai cara untuk menegakkan diagnosis AVM antara lain Cerebral MR Angiografi, Cerebral CT Angiografi, Cerebral DSA dan Transcranial Doppler (TCD). TCD merupakan suatu pemeriksaan berbasis ultrasound yang bersifat non invasif, murah dan bersifat real time dalam memeriksa kondisi hemodinamik intraserebral pada kasus AVM dan dapat menentukan feeder artery pada serebral AVM. ${ }^{2}$

\section{LAPORAN KASUS}

\section{Kasus 1}

Laki-laki 34 tahun dengan kejang parsial, pada pemeriksaan $C T$ scan kepala mengarah pada suatu gambaran AVM di lobus frontalis dekstra kemudian pasien dilakukan TCD didapatkan peningkatan Mean Flow Velocity (MFV) dan penurunan Pulsatility Index (PI) $<0,5$ pada Right Anterior Cerebral Artery (R-ACA) menunjukkan bahwa R-ACA sebagai feeder artery.

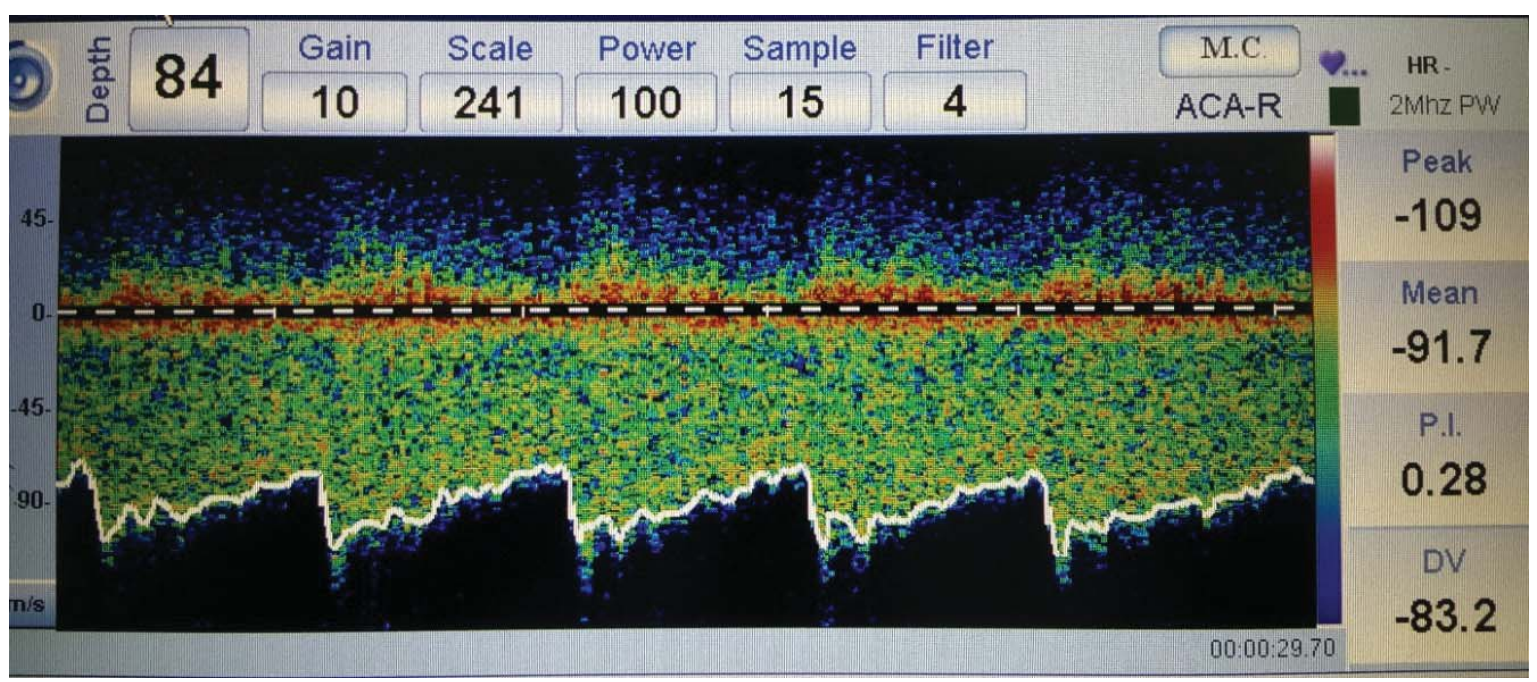




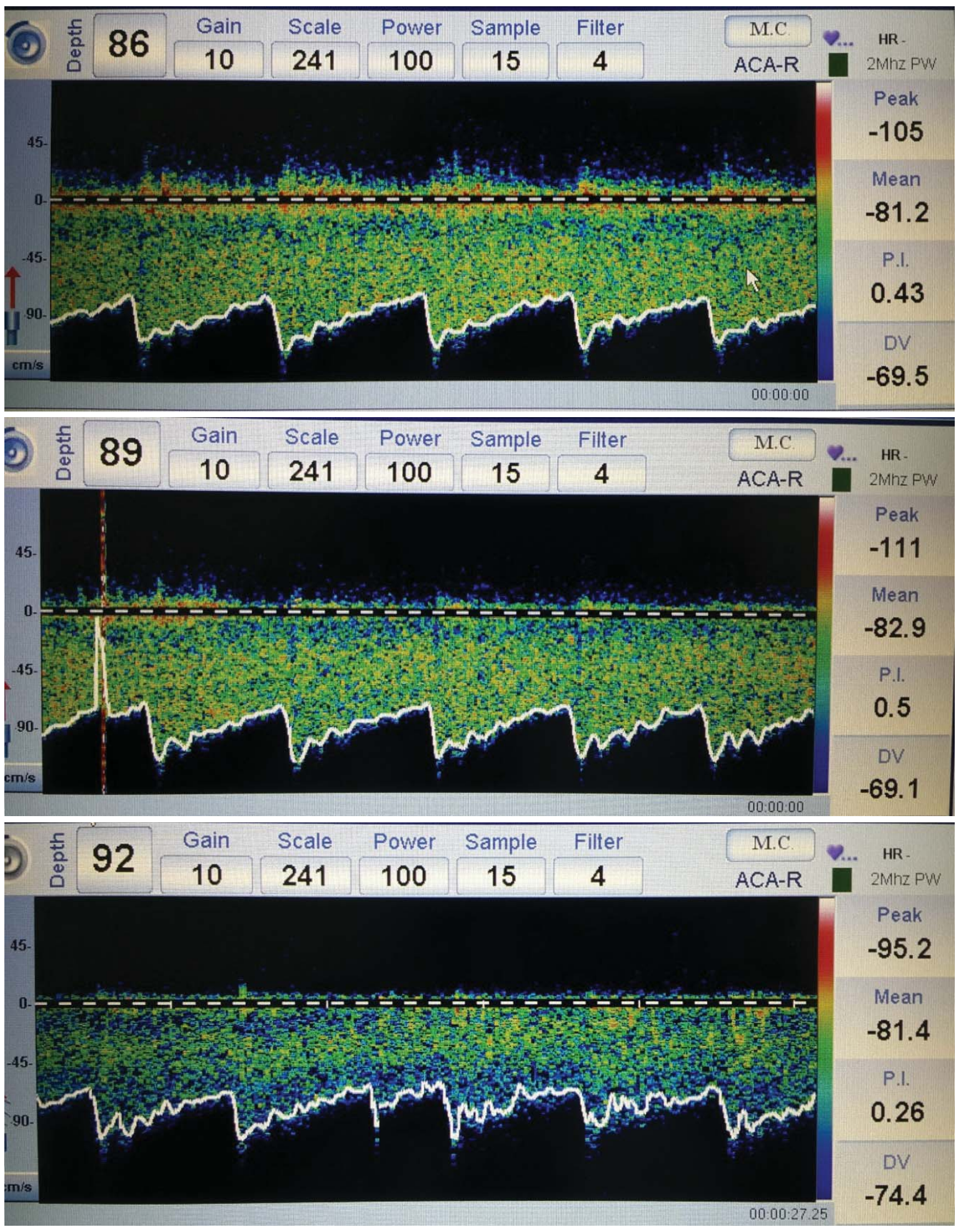

Gambar 1. Hasil pemeriksaan TCD dengan insonansi pada Right Anterior Cerebral Artery dengan kedalaman yang bertingkat mulai dari $84 \mathrm{~mm}, 86 \mathrm{~mm}, 89 \mathrm{~mm}$ dan $92 \mathrm{~mm}$. Pada empat kedalaman yang diambil didapatkan MFV diatas nilai normal dan PI sangat rendah $(<0,5)$. 
Menentukan letak feeding
secara struktural dilakukan pemeriksaan lanjutan berupa Cerebral MRA dan didapatkan hasil AVM di
Lobus Frontalis kanan dengan feeding dari arteri serebri anterior kanan dan draining vein ke sinus sagitalis inferior.
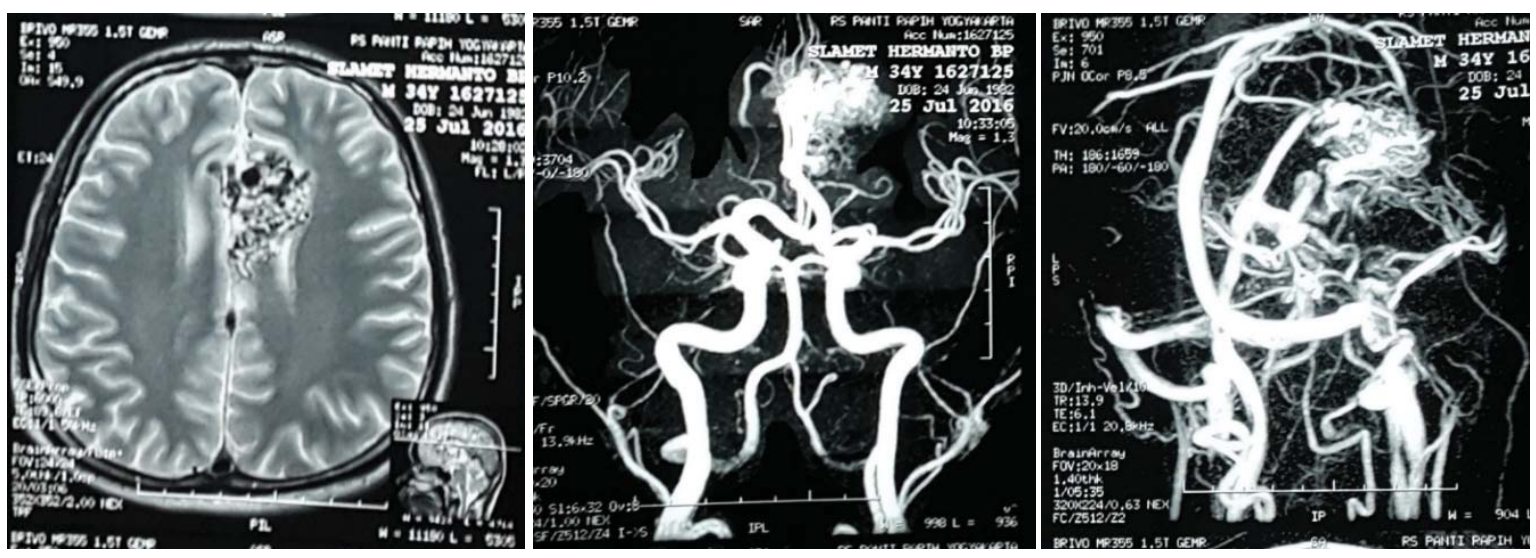

Gambar 2. Konfirmasi dengan cerebral MRA didapatkan gambaran AVM pada lobus Frontalis kanan dengan feeding dari arteri serebri anterior kanan.

Kasus ini didapatkan kesamaan letak feeding artery dari pemeriksaan TCD dan setelah dilakukan konfirmasi dengan cerebral $M R A$.

\section{Kasus 2}

Perempuan 37 tahun dengan penurunan kesadaran, pada pemeriksaan $C T$ scan kepala tampak perdarahan intraventrikuler dan AVM pada lobus ocipital kiri, pada saat kondisi pasien stabil dilakukan pemeriksaan TCD didapatkan peningkatan Mean Flow Velocity (MFV) dan penurunan Pulsatility Index (PI) $<0,5$ pada Left Middle Cerebral Artery (L-MCA) menunjukkan bahwa L-MCA sebagai feeder artery dan didapatkan peningkatan MFV pada L-PCA tanpa disertai dengan penurunan tajam dari PI.

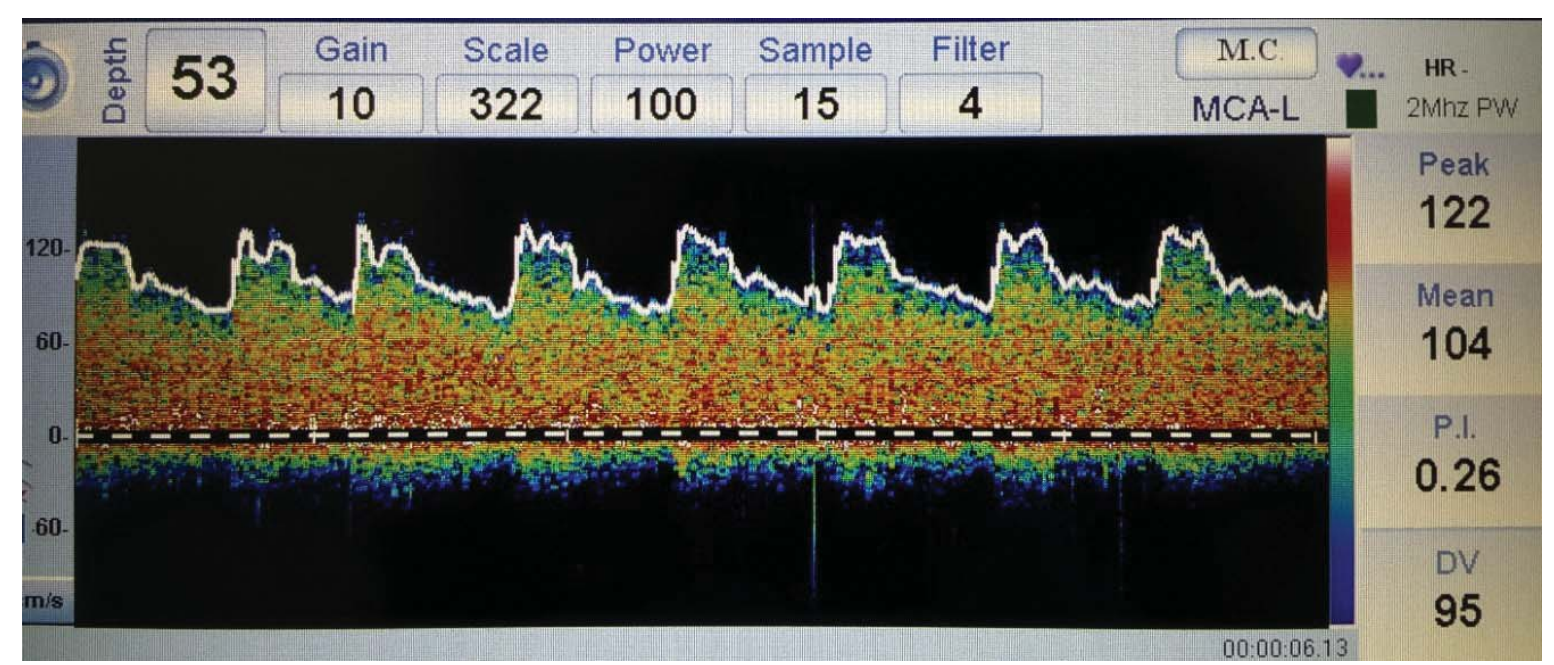




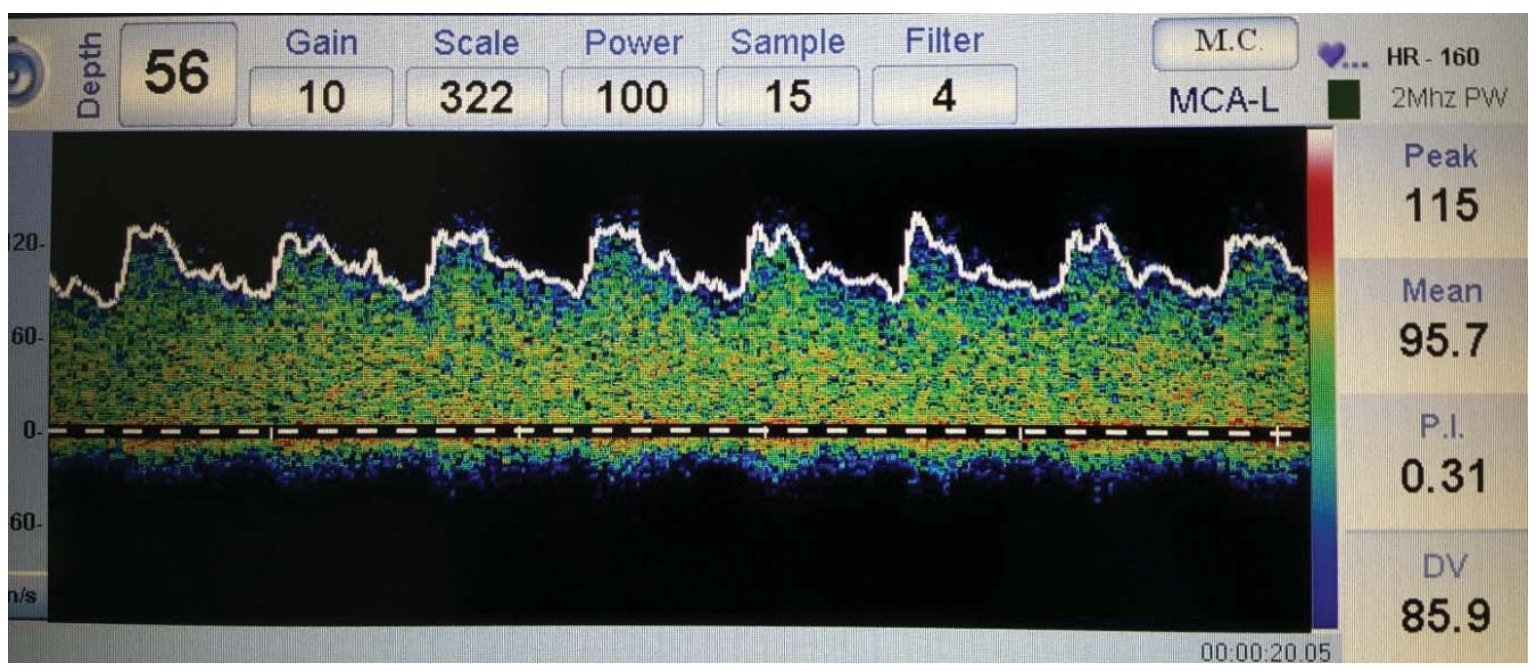

Gambar 3. Hasil pemeriksaan TCD dengan insonansi pada Left Middle Cerebral Artery dengan kedalaman yang bertingkat mulai dari $53 \mathrm{~mm}$ dan $56 \mathrm{~mm}$. Pada kedalaman yang diambil didapatkan MFV diatas nilai normal dan PI sangat rendah $(<0,5)$ yaitu 0,26 dan 0,31 .

Konfirmasi pemeriksaan dengan Cerebral MRA didapatkan Gambaran AVM berukuran $6 \times 4 \mathrm{~cm}$ pada lobus occipital kiri, feeding

artery curiga berasal dari cabang arteri cerebri posterior kiri dan cabang arteri cerebri media kiri, draining vein kedalam sinus sagitalis superior.
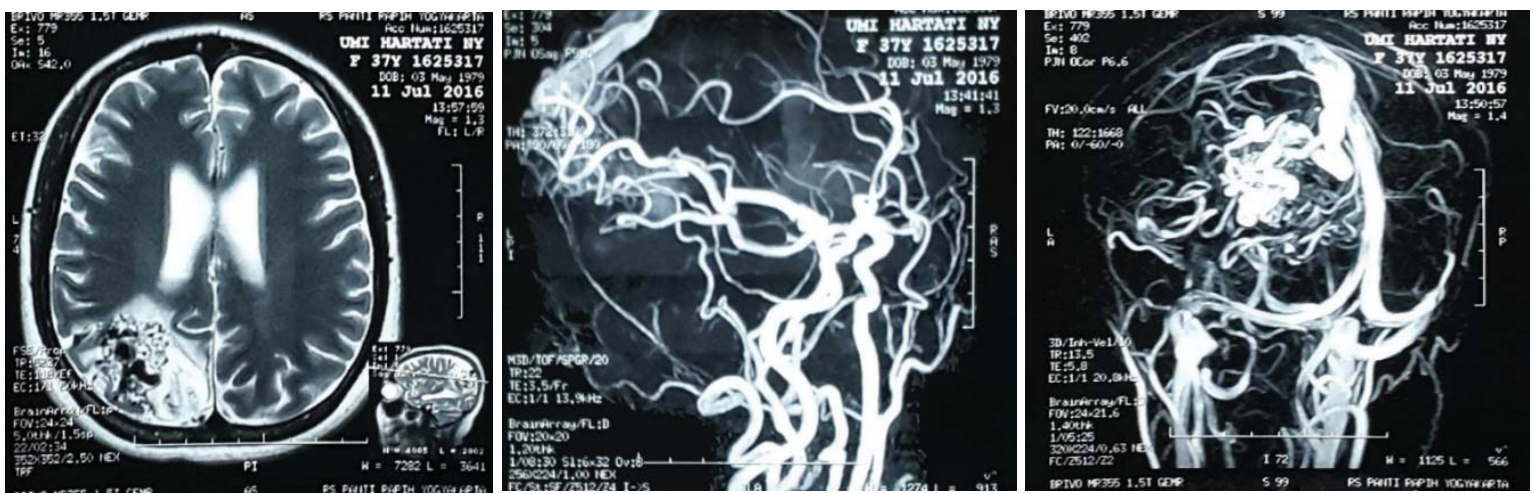

Gambar 4. Konfirmasi dengan cerebral MRA didapatkan gambaran AVM pada lobus Occipitalis kiri dengan dua feeding artery curiga berasal dari cabang arteri cerebri posterior kiri dan cabang arteri cerebri media kiri

Pada kasus ini terdapat perbedaan hasil antara TCD dan Cerebral MRA yaitu adanya feeding artery yang terlihat pada MRA diamana Left Posterior Cerebal Artery tidak menunjukkan kriteria sebagai feeder pada pemeriksaan TCD, pada pemeriksaan TCD kasus ini pada segmen L-PCA memang didapatkan peningkatan Mean Flow Velocity tanpa diikuti oleh penurunan tajam dari pulsatility index (PI masih lebih besar dari 0,5). 


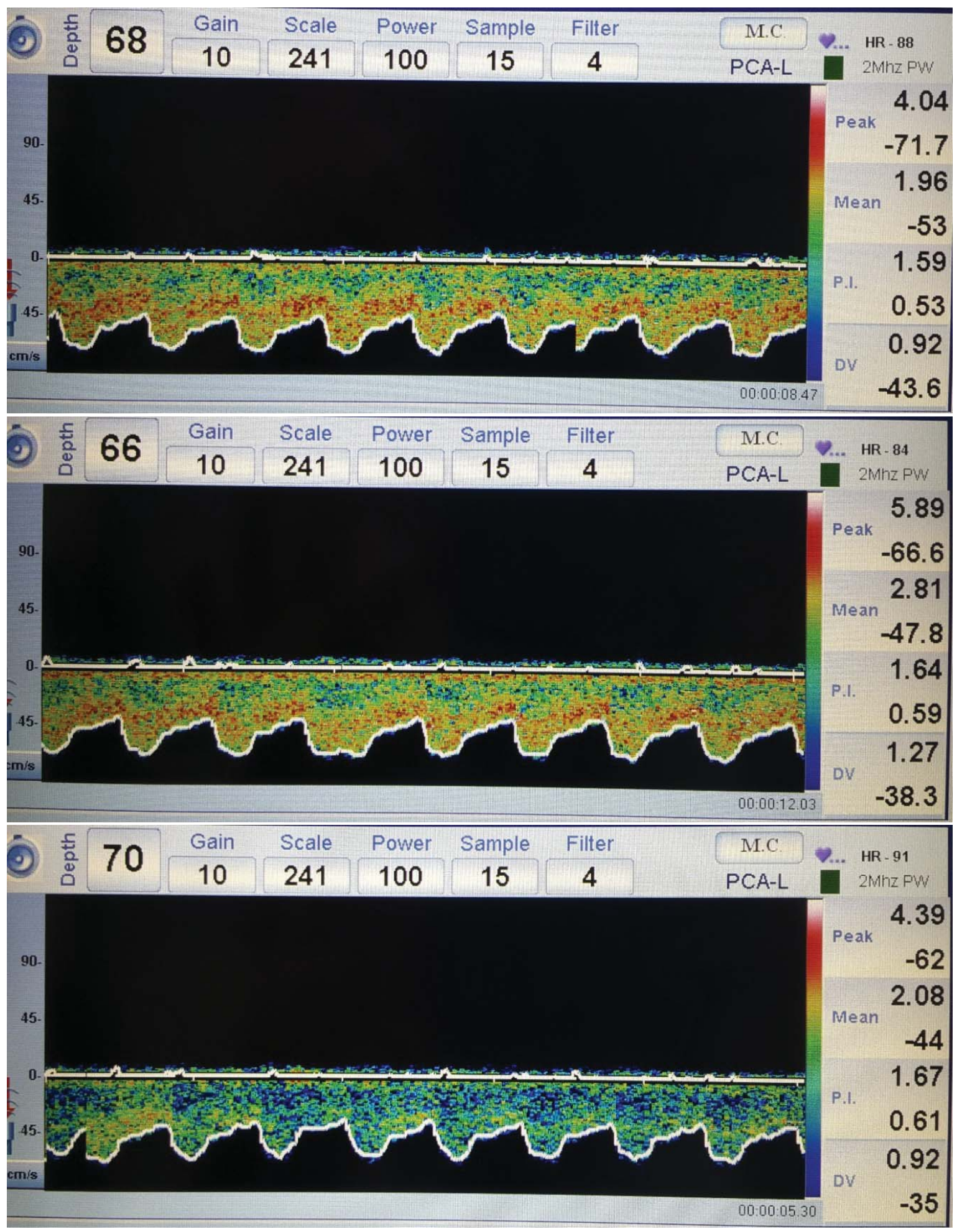

Gambar 5. Hasil pemeriksaan TCD dengan insonansi pada Left Posterior Cerebral Artery dengan kedalaman yang bertingkat mulai dari $66 \mathrm{~mm}, 68 \mathrm{~mm}$ dan $70 \mathrm{~mm}$. Tidak menunjukan PI yang rendah $(<0,5)$. 


\section{DISKUSI}

TCD mampu mendeteksi abnormal MFV dan PI pada AVM feeder. Sebuah feeder AVM adalah dilatasi pembuluh darah karena adanya peningkatan dari volume darah dalam pembuluh darah tersebut. Hal ini menyebabkan peningkatan MFV dan dilatasi yang besar dari lumen pembuluh darah menyebabkan pulsasi arteri menjadi menurun yang tampak pada sangat rendahnya pulsatility index..$^{3,4}$ Kasus pertama merupakan kasus yang sangat ideal karena kriteria AVM pada pemeriksaan TCD terpenuhi.

Kasus kedua sangat menarik karena pada pemeriksaan TCD tidak terlihat L-PCA sebagai feeder dari AVM sedangkan konfirmasi angiografi mengambarkan adanya 2 feeder. Hal ini kemungkinan disebabkan oleh beberapa hal antara lain sudut insonansi pada pemeriksaan TCD, sensitifitas pemeriksaan TCD pada AVM, dan adanya TCD-AVM grade yang rendah (AVM dengan ukuran $<2 \mathrm{~cm}$ (grade 1) memiliki PI > 0,5). 5, 6 MFV dan PI sebagai indikator pada feeder AVM memiliki sensitifitas yang tidak sama, MFV yang tinggi memiliki sensitifitas $83 \%$ pada kasus AVM sedangkan PI yang sangat rendah sensitifitasnya $50 \%$, sehingga PI yang rendah saja tidak dapat menjadi indikator untuk suatu feeder AVM. ${ }^{7}$

\section{KESIMPULAN}

TCD merupakan suatu pemeriksaan non invasif yang cukup murah untuk menentukan feeder artery pada kasus AVM, dan dapat digunakan untuk skrining awal dan menegakkan diagnosis pada pasien dengan kecurigaan serebral AVM, tetapi secara struktural tetap harus dilakukan pemeriksaan angiografi pada kasus-kasus AVM.

Publikasi ini telah dipresentasikan pada acara Solo Update on Neurology, Oktober 2016.

\section{DAFTAR PUSTAKA}

1. Lindsay KW \& Bone I, Neurology and Neurosurgery Illustrated. UK, Churchil Livingstone. Hlm 288289. 2003.

2. Alexandrov AV. Neurovascular Examination The Rapid Evaluation of Stroke Patient Using Ultrasound Waveform Interpretation. New York. Wiley Blackwell. 2013.

3. Alexandrov AV \& Joseph M. Trancranial Doppler An Overview of Its Clinical Application. Journal of Emergency and Intensive Care Medicine. Vol4 N1. 2000.

4. Nichols FT, Adams RJ, Jones AM. TCD and Sickle Cell Disease. Dalam: Alexandrov AV \& Grotta JC. Cerebrovascular Ultrasound in Stroke Prevention and Treatment. New York: Blackwell; Hlm 138. 2004.

5. Katz M L \& Alexandrov A. A Practical Guide to Transcranial Doppler Examination. USA. Summer Pub. Hlm 110-111. 2003.

6. Kilic T, Pamir MN, Budd S, Ozek MM, Erzen C. Grading and Hemodynamic Follow Up Study of AVM with Transcranial Doppler Ultrasonography, J Ultrasound Med. 17:729-38. 1998.

7. Lindegaard KF, Aaslid R, Nornes H, Cerebral Arteriovenous Malformation. Dalam: Transcranial Doopler Sonography. New York. Springer-Verlag. Hlm 87-89. 1986. 